\title{
Modulation of Alveolar Macrophage-driven Fibroblast Proliferation by Alternative Macrophage Mediators
}

\author{
P. B. Bitterman, M. D. Wewers, S. I. Rennard, S. Adelberg, and R. G. Crystal \\ Pulmonary Branch, National Heart, Lung, and Blood Institute, National Institutes of Health, Bethesda, Maryland 20892
}

\begin{abstract}
Tissue fibrosis results, in part, from an interaction between growth regulatory molecules released by mononuclear phagocytes and fibroblasts. In the chronic interstitial lung disorders, alveolar macrophages, the mononuclear phagocytes of the lung, are known to spontaneously release two growth factors for fibroblasts, fibronectin and alveolar macrophage-derived growth factor (AMDGF) that together stimulate nonreplicating lung fibroblasts to divide. In addition to these two primary growth promoting signals, alveolar macrophages are able to release other mediators that may have a potential role in modulating lung fibroblast replication in response to these primary signals, including interferon $\boldsymbol{\gamma}(\mathrm{IFN} \gamma)$, prostaglandin $\mathrm{E}_{2}\left(\mathrm{PGE}_{2}\right)$, and interleukin 1 (IL-1). To evaluate this possibility, we examined the effect of each of these other mediators on lung fibroblast replication in response to fibronectin and AMDGF in serum-free, defined medium. IFN $\gamma$ had no effect on fibroblast replication. In contrast, $\mathbf{P G E}_{2}$ resulted in a dose-dependent inhibition of fibroblast replication in response to fibronectin and AMDGF with $50 \%$ of the maximum inhibition observed at a PGE 2 concentration of $<10 \mathrm{ng} / \mathrm{ml}$. IL-1, while not active as a primary growth promoting signal, at concentrations of 4-10 $\mathrm{U} / \mathrm{ml}$, augmented fibroblast replication in response to fibronectin and AMDGF by 10 to $15 \%$. Temporally, the growth augmenting effect of IL-1 occurred early in the $G_{1}$ phase of the cell cycle. These data indicate that lung fibroblast replication in response to two of the primary growth promoting signals spontaneously released by alveolar macrophages in the interstitial lung disorders, while uninfluenced by IFN $\gamma$, can be inhibited by $\mathrm{PGE}_{2}$ and modestly augmented by IL-1. Understanding the relevant fibroblast growth modulatory signals within the alveolar microenvironment in the chronic interstitial disorders may lead to rational therapeutic strategies designed to interrupt the fibrotic process.
\end{abstract}

\section{Introduction}

Mononuclear phagocytes are thought to play a central role in the pathogenesis of tissue fibrosis by releasing growth regulatory molecules for fibroblasts (1-9). This concept has received strong experimental support in the fibrotic process of the chronic in-

Address reprint requests to Dr. Crystal, Building 10, Room 6D03, National Institutes of Health, Bethesda, MD 20892. Dr. Bitterman's present address is Pulmonary Division, Department of Medicine, University of Minnesota, Minneapolis, MN. Dr. Rennard's present address is Pulmonary Division, Department of Medicine, University of Nebraska, Omaha, NE. 1985.

Received for publication 15 July 1985 and in revised form 18 October

The Journal of Clinical Investigation, Inc.

Volume 77, March 1986, 700-708 terstitial lung disorders. These disorders are invariably associated with alveolar inflammation in which activated alveolar macrophages, the mononuclear phagocytes of the lung, comprise an important component (10-13). Within any region of the alveolar wall, an accumulation of alveolar macrophages precedes the increase in fibroblast number that characterizes the fibrotic process $(12,13)$. Furthermore, alveolar macrophages from most patients with interstitial fibrosis spontaneously release two primary growth factors for lung fibroblasts, fibronectin and alveolar macrophage-derived growth factor (AMDGF), ${ }^{1}$ that, together with transferrin, can stimulate fibroblasts to proliferate, thus leading to an expansion of fibroblast numbers within the alveolar structures (3-5). Specifically, fibronectin, a 440,000-D glycoprotein, acts as a "competence factor" that delivers a growth promoting signal to nonreplicating lung fibroblasts early in the $\mathrm{G}_{1}$ phase of the cell cycle, making them responsive to the subsequent presence of a second growth promoting signal later in $\mathrm{G}_{1}$ (progression factor) (4). AMDGF, an 18,000-D peptide, delivers a progression signal later in $G_{1}$ permitting lung fibroblasts previously exposed to a competence signal (e.g., fibronectin) to replicate (2). In the context of these observations, alveolar macrophage-released fibronectin and AMDGF are thought to be the primary signals that drive fibroblasts to expand in numbers in the interstitial lung disorders.

In addition to the primary signals of fibronectin and AMDGF, there are several well characterized alveolar macrophage mediators that may also play a role in modulating lung fibroblast replication. These include interferon $\gamma(\mathrm{IFN} \gamma)$, prostaglandin $\mathrm{E}_{2}\left(\mathrm{PGE}_{2}\right)$, and interleukin 1 (IL-1). IFN $\gamma$, a 25,000$\mathrm{D}$ glycoprotein, is spontaneously released by alveolar macrophages in several interstitial lung disorders $(14,15)$. Besides its multiplicity of activities in modulating immune processes (16), IFN $\gamma$ is generally known to down-regulate cell replication (17), although its influence on the proliferation of diploid human fibroblasts in defined conditions is unknown. $\mathrm{PGE}_{2}$, a 352-D cyclooxygenase metabolite of arachidonic acid, is spontaneously released by normal alveolar macrophages. $\mathrm{PGE}_{2}$ is known to suppress serum growth factor-driven proliferation of diploid human fibroblasts $(18,19)$. IL-1, a 12,000-15,000-D protein, can be produced by alveolar macrophages, although to a far less extent than by blood monocytes $(20,21)$. Observations by Schmidt et al. (6) indicated that IL-1 will augment serum stimulated diploid human fibroblast replication. Consistent with this finding, Estes and co-workers (22) have shown that IL-1 will augment 3T3 cell replication in plasma containing suboptimal concentrations of platelet-derived growth factor (PDGF). Thus, while fibronectin and AMDGF are sufficient to drive fibroblasts to proliferate, it is reasonable to hypothesize that the primary

1. Abbreviations used in this paper: AMDGF, alveolar macrophage-derived growth factor; DME, Dulbecco's modified Eagle's medium; FGF, fibroblast growth factor; IFN $\gamma$, interferon $\gamma$; IL-1, interleukin 1; PDGF, platelet-derived growth factor; $\mathrm{PGE}_{2}$, prostaglandin $\mathrm{E}_{2}$. 
signals delivered by fibronectin and AMDGF may be modulated by these other macrophage products.

In this regard, the purpose of the present study was to determine the potential biological importance of IFN $\gamma, \mathrm{PGE}_{2}$, and IL-1 to the process of lung fibroblast replication in response to fibronectin and AMDGF in serum-free defined conditions. The data indicate that $\mathrm{PGE}_{2}$ is able to inhibit lung fibroblast replication in response to fibronectin and AMDGF, while IFN $\gamma$ has no effect. In contrast, while IL-1 is unable to provide a primary growth signal to nonreplicating fibroblasts, it is able to modestly augment fibroblast replication in response to fibronectin and AMDGF.

\section{Methods}

\section{Preparation of mediators}

Fibronectin. Fibronectin was purified from plasma in two ways: (a) gelatin-sepharose affinity chromatography as described by Engvall and Ruoslahti (23) followed by gel filtration, or (b) gelatin sepharose followed by heparin agarose affinity chromatography as described by Hayashi and Yamada (24). The biological activity of both types of preparations was identical. Aliquots of purified fibronectin were stored frozen in liquid nitrogen vapor. Before use in cell culture, each aliquot was rapidly thawed, dialyzed $\left(16 \mathrm{~h}, 22^{\circ} \mathrm{C}\right)$ against Dulbecco's modified Eagle's medium (DME; MA Bioproducts, Walkersville, MD), passed through a $0.22-\mu \mathrm{m}$ filter, and analyzed for fibronectin content using an enzyme-linked immunosorbent assay (ELISA) as previously described (25).

$A M D G F$. AMDGF was prepared by pooling the spontaneous secretory products of $\sim 10^{9}$ alveolar macrophages obtained from 13 patients with interstitial lung disease. AMDGF was partially purified from this material by sequential anion exchange and gel filtration chromatography as previously described (2). From $2.2 \mathrm{mg}$ of macrophage secretory protein, $3.2 \mu \mathrm{g}$ of AMDGF were obtained, representing a 1,100-fold purification. Further purification of AMDGF was attempted using a variety of techniques, but due to limited quantities of crude factor and its apparent lability, significant amounts of further purified material were not available for use in these studies. However, additional characteristics of AMDGF were determined. These characteristics included: activity did not bind to cation exchange resins at neutral $\mathrm{pH}$; activity lost during isoelectric focusing (unstable in ampholines), hydrophobic chromatography, and polyacrylamide gel electrophoresis; activity destroyed by boiling and trypsinization; and activity not lipid soluble. AMDGF was identical biologically and biochemically to that previously described (2-4).

Interleukin 1. IL-1 was prepared from supernates of LPS-stimulated alveolar macrophages (pooled supernates from $5 \times 10^{8}$ macrophages from eight patients with interstitial lung disorders) and blood monocytes ( $10^{9}$ from a single donor leukophoresis) by sequential anion exchange and gel filtration chromatography followed by preparative isoelectric focusing as previously described (21). Monocyte and macrophage IL-1 were biochemically and biologically indistinguishable.

Platelet-derived growth factor (PDGF). PDGF was partially purified from human platelets by sequential cation exchange, gel filtration, and preparative isoelectric focusing as described by Vogel et al. (26).

Other mediators. $\mathrm{PGE}_{2}$ was obtained from Sigma Chemical Co. (St. Louis, $\mathrm{MO}$ ) and was prepared as a stock solution in ethanol and stored at $-20^{\circ} \mathrm{C}$ until used. The final volume of ethanol in cell cultures was $<0.1 \%$, a concentration without effects on fibroblast replication. IFN $\gamma$ was obtained from two sources: recombinant IFN $\gamma$, from Genzyme Corp. (Boston, MA); and nonrecombinant material, from Meloy Laboratories, Inc. (Springfield, VA). Both materials were used in all experiments reported. The quantitation of IFN $\gamma$ was performed using a standard WISH cell bioassay (15). Fibroblast growth factor (FGF) and insulin were from Collaborative Research, Inc. (Waltham, MA).
Assessment of the ability of alveolar macrophage products to modulate fibroblast replication

The experimental design for the studies of fibroblast growth was based on the dual control model of the cell cycle (27). According to this concept, there are at least two classes of growth factors for fibroblasts. Competence factors (e.g., PDGF, FGF, and fibronectin) act early in $G_{1}$, enabling an appropriate target cell to respond later in $G_{1}$ to the subsequent presence of progression factors (e.g., insulin, insulin-like growth factors, and AMDGF). Both a competence and progression factor are required for optimal fibroblast replication. This information forms the basis for a growth assay in which none, one, or both classes of factors are present in the fibroblast culture with a test factor.

All studies of fibroblast replication were performed using human lung fibroblasts (HFL-1; American Type Culture Collection CCL 153) maintained in DME plus $10 \%$ calf serum (MA Bioproducts) in an atmosphere of $90 \%$ air, $10 \% \mathrm{CO}_{2}$, and used before the 25 th population doubling. Unless specifically noted, all fibroblast growth assays were performed in serum-free defined medium containing $1 \mathrm{mg} / \mathrm{ml}$ albumin (Sigma Chemical Co.), and $10 \mu \mathrm{g} / \mathrm{ml}$ saturated transferrin (Collaborative Research, Inc.). This culture system permitted study of the effect of each growth factor on fibroblast replication without the complexity introduced by the numerous growth regulatory molecules in serum.

Growth augmentation. In each instance, growth augmentation was assessed by determining cell number. In some experiments, results were corroborated using autoradiography of $\left[{ }^{3} \mathrm{H}\right]$ thymidine incorporation into DNA carried out as previously described (2). Two separate strategies were employed to detect growth promoting effects. The first was designed to assess the ability of a growth factor to signal nonreplicating cells to enter the cell cycle, and the second to examine the ability of a factor to increase replication of cells already signalled to divide.

(a) To assess the ability of a growth factor to signal nonreplicating fibroblasts $\left(G_{0} / G_{1}\right.$, referred to as " $G_{1}$," phase of the cell cycle) to divide, the cells were cultured with a test factor alone, or in combination with defined growth factors, either a known competence factor or a known progression factor, as previously described (2). Nonreplicating fibroblasts were prepared by seeding $35 \times 10^{3}$ fibroblasts/35-mm dish (Falcon Labware, Becton-Dickinson \& Co., Oxnard, CA) in $2 \mathrm{ml} \mathrm{DME,} 0.4 \%$ calf serum (for cell counts), or at an equivalent density in eight-chamber slides (Lab-Tek, Miles Scientific, Div. of Miles Laboratories, Inc., Napersville, IL) in $0.4 \mathrm{ml}$ of the same medium (for autoradiography). For both cell count and autoradiographic assays, after $3 \mathrm{~d}$, the cells were rinsed three times with assay medium and cultured $\left(37^{\circ} \mathrm{C}, 24 \mathrm{~h}\right)$ in that same medium. The resultant nonreplicating fibroblasts $(<6 \%$ labeled nuclei/24 h) were cultivated with the various growth factors and the growth response was assessed.

(b) To assess the ability of a factor to augment replication in cells that were signaled to divide, nonreplicating fibroblasts were signaled to traverse the cell cycle either by the complete set of growth promoting signals present in serum or by defined growth factors (both a competence and progression factor). These growth factor-signaled cells were cultured with the test factor for several days with cell number determined each day. Growth factor-signaled cells cultured without the test factor served as a control.

Growth inhibition. The general approach used was to incubate noncycling cells with the putative inhibitor concomitant with the addition of the growth promoting signals. Growth inhibition was assessed by determining cell number as described above.

\section{Ability of IFNy to modulate lung fibroblast replication induced by defined growth factors}

Because of its apparent ability to augment replication in some cells (e.g., T lymphocytes) (28) and to inhibit replication in most cells (e.g., several tumor lines) (17), IFN $\gamma$ was evaluated for its ability to either augment or inhibit lung fibroblast replication.

Augmentation. To assess the ability of IFN $\gamma$ to act as a primary growth promoting signal for lung fibroblast replication, cells were cultured 
with IFN $\gamma$ in the presence of either a known competence or progression factor and the resultant increase in cell number determined. In the test for progression activity, nonreplicating fibroblasts were cultured with varying concentrations of IFN $\gamma$ (both recombinant and nonrecombinant) plus a competence factor (PDGF, $0.5 \mathrm{U} / \mathrm{ml}$; FGF, $25 \mathrm{ng} / \mathrm{ml}$; or fibronectin, $1.0 \mu \mathrm{g} / \mathrm{ml}$ ) with cell number determined after $72 \mathrm{~h}$ using an electronic particle counter (Coulter ZBI; Coulter Electronics, Inc., Hialeah, FL). In the test for competence activity, nonreplicating fibroblasts were similarly cultured with IFN $\gamma$ except in this case with a progression factor (insulin, $25 \mu \mathrm{g} / \mathrm{ml}$ ) or AMDGF $(5 \mathrm{ng} / \mathrm{ml})$, with cell number determined after $72 \mathrm{~h}$. As a positive control, fibroblasts were cultured with a known competence factor together with a known progression factor.

To determine whether IFN $\gamma$ could augment fibroblast replication in cells stimulated to divide by defined growth factors, fibroblasts were cultured with IFN $\gamma$ in addition to both a competence and progression factor. This was accomplished by adding varying amounts of IFN $\gamma$ and midrange concentrations of a competence factor (fibronectin, $1.0 \mu \mathrm{g} / \mathrm{ml}$ or FGF, $25 \mathrm{ng} / \mathrm{ml}$ ) plus a progression factor (AMDGF, $5 \mathrm{ng} / \mathrm{ml}$ or insulin, $25 \mu \mathrm{g} / \mathrm{ml}$ ) to nonreplicating fibroblasts. Cultures were continued $5 \mathrm{~d}$ with cell counts performed daily.

Inhibition. The ability of IFN $\gamma$ to inhibit fibroblast replication was assessed by culturing fibroblasts with IFN $\gamma$ concomitant with a stimulus to divide. To accomplish this, nonreplicating fibroblasts were signaled to divide by optimal concentrations of a competence factor (fibronectin, $2.0 \mu \mathrm{g} / \mathrm{ml}$ or FGF, $50 \mathrm{ng} / \mathrm{ml}$ ) plus a progression factor (AMDGF, $10 \mathrm{ng} /$ $\mathrm{ml}$ or insulin, $50 \mu \mathrm{g} / \mathrm{ml}$ ). Varying amounts of IFN $\gamma$ (both recombinant and nonrecombinant) were added at the time of addition of the growth factors with cell number determined daily for $5 \mathrm{~d}$.

\section{Ability of $P G E_{2}$ to inhibit fibroblast replication induced by defined growth factors}

$\mathrm{PGE}_{2}$ inhibition of fibroblast replication was examined by culturing fibroblasts with $\mathrm{PGE}_{2}$ concurrent with the addition of fibronectin plus AMDGF as described above for IFN $\gamma$, except that varying amounts of $\mathrm{PGE}_{2}(1,10,50$, and $100 \mathrm{ng} / \mathrm{ml})$ were added at the time of addition of the growth factors with cell number determined daily for $3 \mathrm{~d}$.

\section{Ability of IL-1 to augment fibroblast replication}

To confirm that, similar to skin fibroblasts, lung fibroblast replication in response to serum could be augmented by IL-1, lung fibroblasts were cultured with serum and varying doses of IL-1 (quantified as previously described) with cell counts performed daily for $5 \mathrm{~d}$.

To determine whether IL-1 could augment fibroblast replication in cells stimulated to divide by defined growth factors in serum-free conditions, fibroblasts were cultured with IL-1 in addition to both a competence and progression factor. This was accomplished by adding varying amounts of IL-1 (1-100 U/ml) and mid-range concentrations of a competence factor (FGF, $25 \mathrm{ng} / \mathrm{ml}$; or fibronectin, $1.0 \mu \mathrm{g} / \mathrm{ml}$ ) plus a progression factor (AMDGF, $5 \mathrm{ng} / \mathrm{ml}$ or insulin, $25 \mu \mathrm{g} / \mathrm{ml}$ ) to nonreplicating fibroblasts. Cultures were continued $5 \mathrm{~d}$ with cell counts performed daily.

To examine the ability of IL-1 to act as a primary growth promoting signal for lung fibroblast replication, we cultured cells with IL-1 in the presence of either a known competence or progression factor and determined the resultant increase in cell number as described above for IFN $\gamma$. In the test for progression activity, nonreplicating fibroblasts were cultured with optimal concentrations of $\mathrm{IL}-1(100 \mathrm{U} / \mathrm{ml})$ plus a competence factor, and in the test for competence activity, nonreplicating fibroblasts were similarly cultured with IL-1 except in this case with a progression factor. Cell number was determined after $72 \mathrm{~h}$. As a positive control, fibroblasts were cultured with a known competence factor together with a known progression factor.

To determine the temporal pattern of the IL-1 augmentation of fibroblast replication, fibroblasts were provided with both a competence and progression factor with IL-1 added subsequently as a function of time. This was accomplished by culturing nonreplicating fibroblasts with both a competence and progression factor (fibronectin, $1.0 \mu \mathrm{g} / \mathrm{ml}$ + AMDGF, $5 \mathrm{ng} / \mathrm{ml}$ or FGF, $25 \mathrm{ng} / \mathrm{ml}+$ insulin, $25 \mu \mathrm{g} / \mathrm{ml}$ ) at the initiation of the experiment $(t=0 \mathrm{~h})$. IL-1 was added $(50 \mathrm{U} / \mathrm{ml})$ as before at $t=0 \mathrm{~h}$ or at later times as indicated in the text. The growth response was assessed by autoradiography with the cells pulsed $\left(\left[{ }^{3} \mathrm{H}\right]\right.$ thymidine; $0.1 \mu \mathrm{Ci} / \mathrm{ml}, 2 \mathrm{Ci} / \mathrm{mmol}$; New England Nuclear, Boston, MA) from 0 to $24 \mathrm{~h}$ and harvested at the termination of the pulse, and in parallel cultures by cell counts at $72 \mathrm{~h}$.

After preliminary studies showed that the action of IL-1 to augment growth was only within 4-6 h after the addition of the primary growth signal(s) (i.e., entirely within the $G_{1}$ phase of the cell cycle), synchronized cells were assessed to define the interval in $G_{1}$ when IL-1 acted. Cells synchronized in $\mathbf{M}$ phase by mitotic detachment (confirmed by flow cytometric determination of DNA content using mithramycin as previously described [29]) were seeded on slides in medium supplemented with either $1 \%$ calf serum or both a competence and progression factor. IL-1 was added at the time of seeding $(t=0 \mathrm{~h})$ or various times afterward $(t=1,2,3,4,5$, or $6 \mathrm{~h})$. To assess the growth response, cells were pulsed with $\left[{ }^{3} \mathrm{H}\right]$ thymidine $(0.1 \mu \mathrm{Ci} / \mathrm{ml})$ at $t=0 \mathrm{~h}$ or at $t=24 \mathrm{~h}$ for $24 \mathrm{~h}$ and harvested for autoradiography.

\section{Results}

Effect of IFN on lung fibroblast replication. In defined conditions, IFN $\gamma$ was not able to modulate lung fibroblast replication promoted by fibronectin and AMDGF or other combinations of known competence and progression factors (Fig. 1). When lung fibroblasts were cultured in $0.4 \%$ serum for $3 \mathrm{~d}$ and for an additional day in serum-free medium, they entered a nonreplicating but viable state. The addition of IFN $\gamma$ alone to cultures of these nonreplicating fibroblasts resulted in no increase in cell number. Similarly, when nonreplicating fibroblasts were cultured with IFN $\gamma$ (up to $1,000 \mathrm{U} / \mathrm{ml}$ ) together with a known competence factor (PDGF, FGF, or fibronectin) in a test for progression activity, or together with a known progression factor (insulin or AMDGF) in a test for competence activity, no effect was observed (Fig. $1 \mathrm{~A}$ ). The positive control, in which a competence factor and progression factor were added to the fibroblast cultures, resulted in a large increase in fibroblast numbers within $3 \mathrm{~d}$. Furthermore, IFN $\gamma$ in concentrations up to $1,000 \mathrm{U} / \mathrm{ml}$ was unable to augment or inhibit fibroblast replication in response to either mid-range or optimal concentrations of a competence factor (fibronectin) plus a progression factor (AMDGF) (Fig. $1 B$ ). IFN $\gamma$ was similarly inactive when FGF and insulin were the growth signals (data not shown).

Inhibition of lung fibroblast replication by $P G E_{2}$. The addition of $\mathrm{PGE}_{2}$ to fibroblasts signaled to divide by both a competence and progression factor resulted in an inhibition of fibroblast replication (Fig. 2). Nonreplicating fibroblasts cultured with optimal concentrations of fibronectin $(2.0 \mu \mathrm{g} / \mathrm{ml})$ + AMDGF $(10 \mathrm{ng} / \mathrm{ml})$ increased in number by up to $112 \%$ within $3 \mathrm{~d}$. The addition of $\mathrm{PGE}_{2}$ to these cultures led to a dosedependent inhibition of the fibroblast growth response ranging from $80 \%$ of the maximum growth response at a $\mathrm{PGE}_{2}$ concentration of $1 \mathrm{ng} / \mathrm{ml}$ to $20 \%$ at a $\mathrm{PGE}_{2}$ concentration of $100 \mathrm{ng} /$ $\mathrm{ml}$. The results were comparable when FGF $(50 \mathrm{ng} / \mathrm{ml})+$ insulin $(50 \mu \mathrm{g} / \mathrm{ml}$ ) were used to signal fibroblast replication (data not shown).

IL-1 augmentation of serum-stimulated lung fibroblast replication. Consistent with its known ability to increase DNA synthesis in skin fibroblasts cultured in serum, IL-1 augmented lung fibroblast replication in response to serum (Fig. 3). As expected, the addition of IL-1 alone to nonreplicating fibroblasts caused no increase in cell number, and the addition of $1 \%$ calf serum 


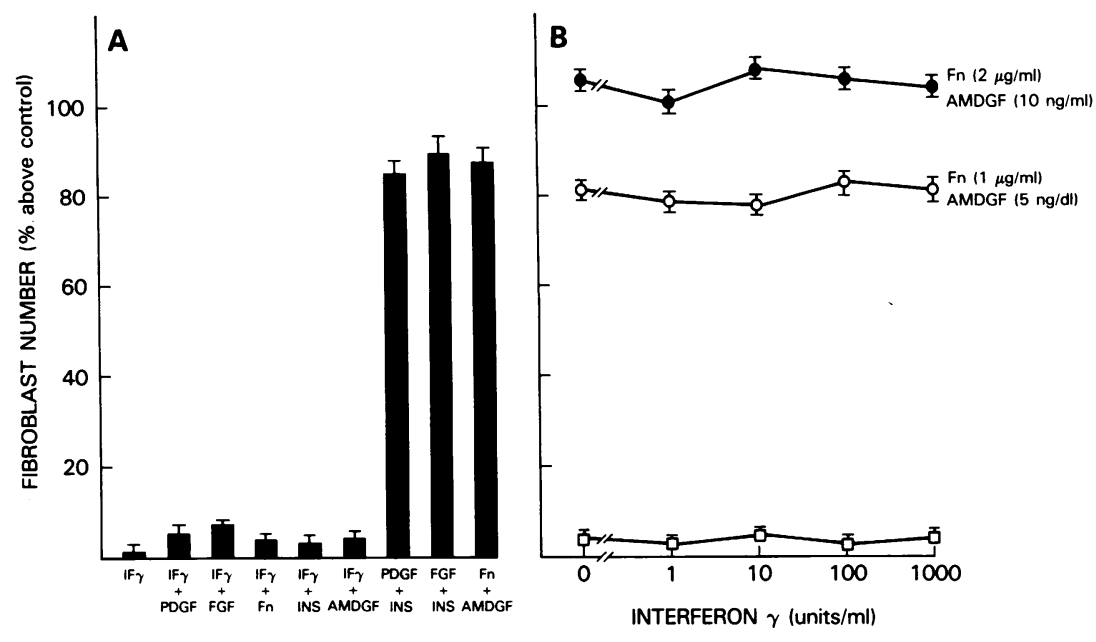

Figure 1. Assessment of the effect of IFN $\gamma$ to modulate lung fibroblast replication alone or in the presence of defined growth factors. $(A)$ Effect of IFN $\gamma$ as a primary growth promoting signal. Nonreplicating fibroblasts were cultured with IFN $\gamma$ alone, or IFN $\gamma$ together with a known competence factor (FGF, $25 \mathrm{ng} / \mathrm{ml}$; PDGF, $0.5 \mathrm{U} / \mathrm{ml}$; or fibronectin $[F n], 1 \mu \mathrm{g} / \mathrm{ml})$ in a test for progression activity, or IFN $\gamma$ together with a known progression factor (insulin [Ins], $25 \mu \mathrm{g} / \mathrm{ml}$; or AMDGF, $5 \mathrm{ng} /$ $\mathrm{ml}$ ) in a test for competence activity. Shown is the percent increase in cell number above that observed in medium alone, $72 \mathrm{~h}$ after growth factor addition. (B) Ability of IFN $\gamma$ to augment or inhibit the replication of lung fibroblasts that have been signaled to divide by fibronectin and AMDGF. Nonreplicating fibroblasts were signaled to divide by either mid-range (o) or optimal (๑) concentrations of fibronectin and AMDGF in the presence of increasing amounts of IFN $\gamma$. For comparison, shown are increasing amounts of IFN $\gamma$ in medium alone ( $\square$ ). Data are presented as the percent increase in cell number above that observed in medium alone, $72 \mathrm{~h}$ after growth factor addition.

resulted in a marked stimulation of cell replication. Of note, however, the presence of IL-1 in the cultures of serum stimulated fibroblasts caused an increase in fibroblast number ranging from 12 to $23 \%$ above the number observed in response to serum alone within $2 \mathrm{~d}$ (Fig. $3 \mathrm{~A}$ ). This increase in cell number was dependent on the concentration of IL-1, with $50 \%$ of the maximum increase observed at 6 to $10 \mathrm{U} / \mathrm{ml}$ (Fig. $3 \mathrm{~B}$ ).

IL-1 augmentation of lung fibroblast replication in response to both a competence and progression factor. In concert with its ability to increase the replication of lung fibroblasts signaled to divide by serum, IL-1 augmented cell replication when lung

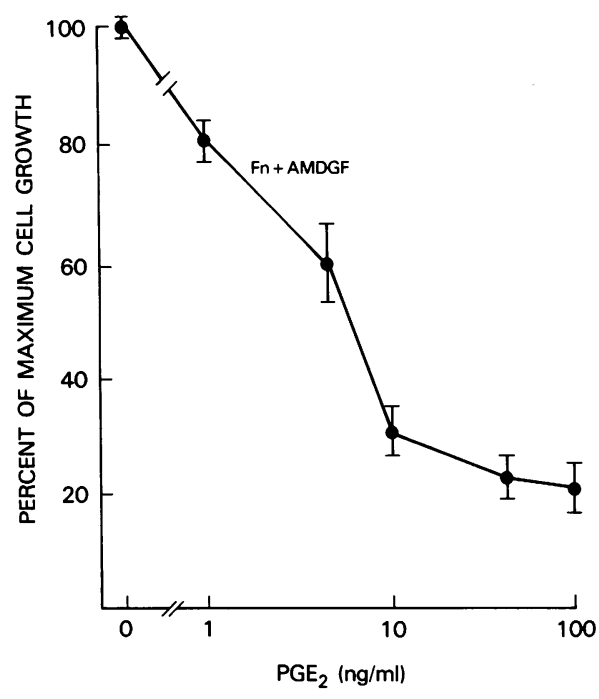

Figure 2. $\mathrm{PGE}_{2}$ inhibition of fibroblast replication in response to fibronectin + AMDGF. Nonreplicating fibroblasts were signaled to divide by fibronectin $(F n ; 2 \mu \mathrm{g} / \mathrm{ml})$ and AMDGF $(10 \mathrm{ng} / \mathrm{ml})$. At the time of growth factor addition, $\mathrm{PGE}_{2}$ was added in varying concentrations. Cultures were continued for $3 \mathrm{~d}$ and cell counts were performed. The growth response with Fn + AMDGF but no added PGE was 101 $\pm 7 \%$ increase in fibroblast number above medium control. The data are presented as a percentage of this growth response at each concentration of $\mathrm{PGE}_{2}$. fibroblasts were signaled to divide by both a competence and progression factor in serum-free defined medium (Fig. 4). Nonreplicating fibroblasts cultured with both a competence and progression factor (either fibronectin + AMDGF or FGF + insulin) demonstrated an increase in cell number within 2-3 d, and continued to divide for up to $5 \mathrm{~d}$ after the addition of growth factors. The addition of IL- 1 to these cultures resulted in a consistent $10-15 \%$ augmentation of the growth observed with either fibronectin plus AMDGF (Fig. $4 A$ ), or FGF plus insulin (data not shown). The augmentation was IL-1 dose-dependent with $50 \%$ of the maximum response observed with 4-8 U/ml of IL-1 (Fig. $4 \mathrm{~B}$ ). Thus, IL-1 caused a modest but reproducible increase in fibroblast replication in defined medium above that observed in response to a competence plus progression factor.

In view of the modest increment in cell number observed with the addition of IL-1 compared with the substantial increase in cell number resulting from the primary growth signals, autoradiography was carried out to confirm these observations. While less than $6 \%$ of fibroblasts cultured in the absence of growth factors synthesized DNA within $24 \mathrm{~h}$, the addition of either FGF plus insulin or fibronectin plus AMDGF resulted in $52-78 \%$ of the cells synthesizing DNA in the same time period. Consistent with the data from direct cell counts, the addition of IL- 1 to the fibroblasts led to an increase in proliferation with nuclear labeling ranging from 59 to $89 \%$. On the average, IL-1 increased the numbers of labeled nuclei by $12 \pm 2 \%$ over that induced by fibronectin plus AMDGF alone. This augmentation was IL- 1 dose dependent with $50 \%$ of the maximum effect observed at 5-10 U/ml (data not shown).

Assessment of the ability of IL-1 to signal nonreplicating fibroblasts to divide. Although able to augment the replication of fibroblasts already signaled to divide, IL-1 was unable to provide either a competence or progression signal to nonreplicating fibroblasts (Fig. 5). Nonreplicating fibroblasts cultured with IL-1 and a known competence factor, either PDGF $(0.5 \mathrm{U} / \mathrm{ml})$, FGF $(25 \mathrm{ng} / \mathrm{ml})$, or fibronectin $(1.0 \mu \mathrm{g} / \mathrm{ml})$ did not increase in number compared with control fibroblasts cultured in media alone. As a positive control, a known progression factor (AMDGF, $5 \mathrm{ng} / \mathrm{ml}$; or insulin, $25 \mu \mathrm{g} / \mathrm{ml}$ ) resulted in a large 


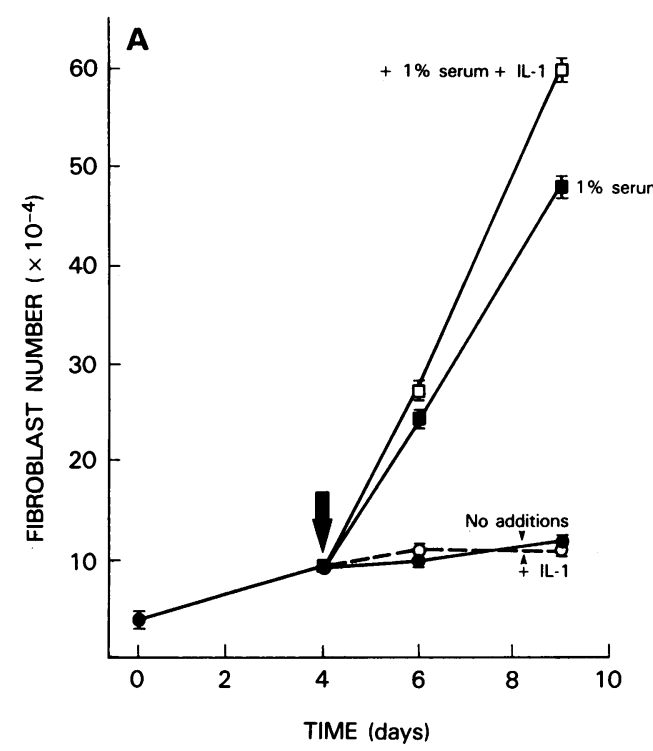

increase in cell number within $3 \mathrm{~d}$. Thus, IL-1 was not a progression factor. Similarly, culturing nonreplicating fibroblasts with IL-1 and a known progression factor (AMDGF or insulin) resulted in no increase in cell number, indicating that IL-1 was not a competence factor. Thus, while IL-1 was able to augment cell replication in response to other growth factors, it was incapable of providing a primary signal that induced nonreplicating fibroblasts to divide.

Temporal pattern of IL-1 augmentation of fibroblast replication. For growth augmentation to be observed, the presence of IL-1 in the fibroblast cultures was required soon after the addition of the primary growth signals (Fig. 6). When IL-1 was added to fibroblasts cultured with fibronectin + AMDGF within $2 \mathrm{~h}$ of growth factor addition, the full augmentation of DNA synthesis (Fig. $6 \mathrm{~A}$ ) and cell number (Fig. $6 \mathrm{~B}$ ) was observed. However, the addition of IL-1 at later times resulted in a progressive decrease in the growth response. The augmentation was not observed if IL-1 was added after $8 \mathrm{~h}$. Similar results were obtained using FGF plus insulin in place of the fibronectin plus AMDGF (data not shown).

Since nonreplicating fibroblasts are known to be arrested in $\mathrm{G}_{1} \sim 12-14 \mathrm{~h}$ before $\mathrm{S}$ phase, the timing of the effects of IL-1 indicated an effect early in the $G_{1}$ phase of the cell cycle. Therefore, early $G_{1}$ was examined in more detail using cells synchronized by mitotic detachment. Using this method, $80-88 \%$ of the cells were in $M$ phase and entered $G_{1}$ within $2 \mathrm{~h}$. The addition of IL- 1 any time after $6 \mathrm{~h}$ following entry into $G_{1}$ resulted in no augmentation of fibroblast DNA synthesis. This confirmed that the effects of IL-1 were cell cycle-specific and occurred in early $\mathrm{G}_{1}$ (data not shown).

\section{Discussion}

Tissue fibrosis, the replacement of normal parenchymal elements with increased numbers of fibroblasts and their connective tissue products, involves, in part, a complex interaction between mononuclear phagocytes and fibroblasts. In the fibrotic lung disorders, alveolar macrophages, the mononuclear phagocytes of the lung, spontaneously release or are able to release several molecules that are either known or putative modulators of lung fibroblast replication including fibronectin, AMDGF, IFN $\gamma$, $\mathrm{PGE}_{2}$, and IL-1. Evaluation of each of these mediators in defined medium indicated that the primary growth promoting signals for nonreplicating lung fibroblasts were fibronectin, which pro-
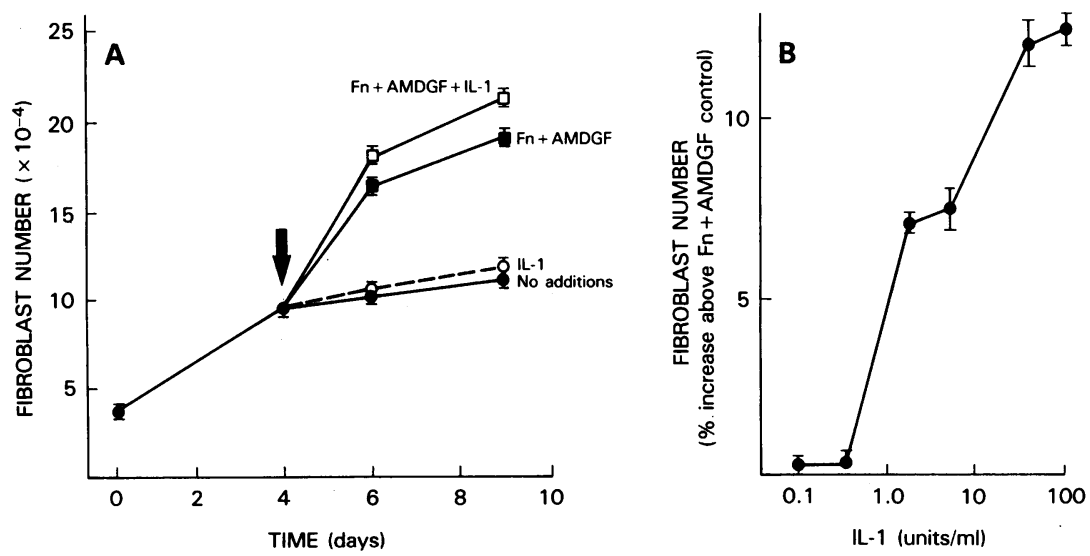

Figure 4. Ability of IL-1 to augment fibroblast replication in serum-free medium in the presence of other defined alveolar macrophage growth factors. $(A)$ Fibroblast replication in response to IL-1 in the absence and presence of defined alveolar macrophage growth factors. On day 4 (arrow), nonreplicating fibroblasts were cultured with fresh assay medium containing no further additions $(\bullet)$, IL-1 alone $(100 \mathrm{U} / \mathrm{ml})(0)$, fibronectin $(F n, 1 \mu \mathrm{g} / \mathrm{ml})$ + AMDGF ( $5 \mathrm{ng} / \mathrm{ml})(\square)$, or Fn + AMDGF + IL$1(\square)$ at the same concentrations. Cultures were continued for $5 \mathrm{~d}$. Shown are cell counts obtained before and after growth factor addition. $(B)$ Relationship between IL-1 concentration and fibroblast replication in the presence of constant amounts of Fn and AMDGF. Experiments were carried out exactly as in Fig. 3 B except serum was omitted and replaced by Fn $(1 \mu \mathrm{g} / \mathrm{ml})+$ AMDGF $(5 \mathrm{ng} / \mathrm{ml})$. Cell counts were performed $5 \mathrm{~d}$ after growth factor addition. Shown for each concentration of IL-1 is the percent increase in fibroblast number above that observed with Fn + AMDGF but without IL-1. 


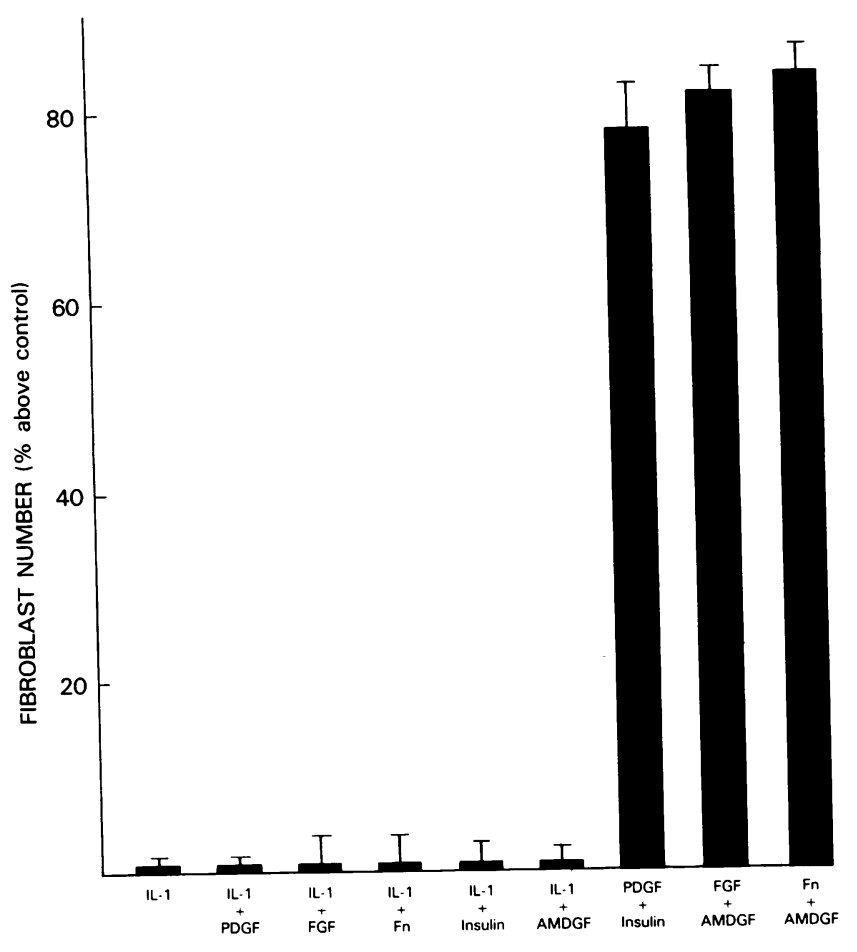

Figure 5. Evaluation of IL-1 as a primary growth promoting signal for fibroblasts. Nonreplicating fibroblasts were cultured with IL-1 alone $(100 \mathrm{U} / \mathrm{ml})$, or IL-1 together with a known competence factor (PDGF, $0.5 \mathrm{U} / \mathrm{ml} ; \mathrm{FGF}, 25 \mathrm{ng} / \mathrm{ml}$; or fibronectin $[F n], 1 \mu \mathrm{g} / \mathrm{ml}$ ) in a test for progression activity, or IL-1 together with a known progression factor (insulin, $25 \mu \mathrm{g} / \mathrm{ml}$; or AMDGF, $5 \mathrm{ng} / \mathrm{ml}$ ) in a test of IL- 1 as a competence factor. Cultures were continued for $3 \mathrm{~d}$ and cell counts were performed. Shown is the percent increase in cell number above that observed in medium alone. Shown also is fibroblast replication in the presence of a known competence and progression factor (PDGF + insulin, FGF + AMDGF, or Fn + AMDGF) as positive controls.

vides a competence signal, and AMDGF, which provides a progression signal. IFN $\gamma$, despite its ability to modulate the replication of transformed cells, was unable to either stimulate or inhibit lung fibroblast replication either alone or in response to fibronectin and AMDGF. In contrast, fibroblast replication in response to fibronectin and AMDGF was inhibited in a dosedependent fashion by $\mathrm{PGE}_{2}$. By itself, IL-1 was unable to stimulate nonreplicating fibroblasts to divide. However, it was able to provide a signal early in $G_{1}$ that augmented fibroblast replication in response to the two primary growth signals, fibronectin and AMDGF. Thus, the alveolar macrophage is a rich source of growth factors as well as a potential source of at least one growth inhibitory molecule, which leads to the concept that the alveolar macrophage may play an important role in both the evolution of pulmonary fibrosis by releasing growth factors, and the eventual limitation of fibroblast replication in part by enhancing $\mathrm{PGE}_{2}$ concentrations in the alveolar microenvironment.

\section{General concepts of pulmonary fibrosis}

Independent of cause, the fundamental anatomical feature of pulmonary fibrosis is an increased number of fibroblasts within the alveolar wall. Qualitative studies in humans $(30,31)$, as well as morphometric studies in animals $(10,11,32)$, indicate a several-fold increase in fibroblast number in these disorders. As a result of this expansion of the lung fibroblast population, there

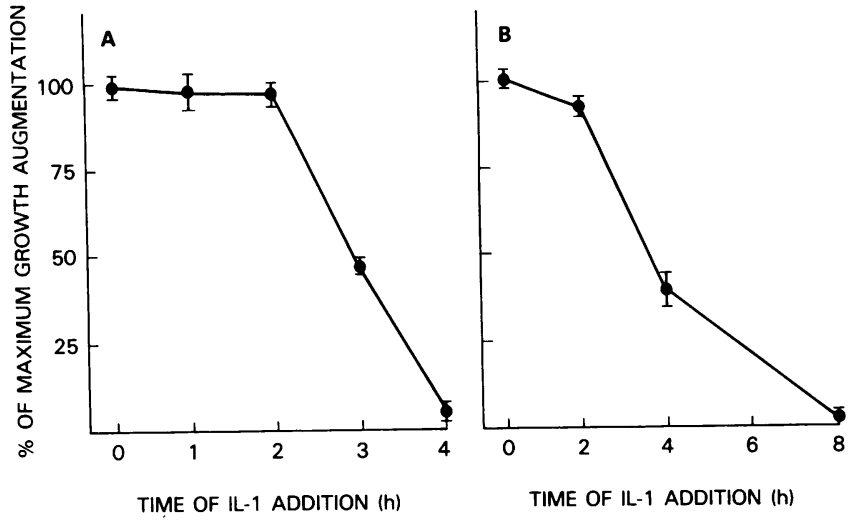

Figure 6. Temporal pattern of IL-1 augmentation of fibroblast replication in the presence of defined alveolar macrophage growth factors. Nonreplicating fibroblasts were cultured with fibronectin $(1 \mu \mathrm{g} / \mathrm{ml})$ + AMDGF $(5 \mathrm{ng} / \mathrm{ml})$ at time $(t)=0 \mathrm{~h}$, and IL-1 $(50 \mathrm{U} / \mathrm{ml})$ was added at $t=0 \mathrm{~h}$ or at various times afterward. The growth response was assessed in two ways: autoradiography of $\left[{ }^{3} \mathrm{H}\right]$ thymidine incorporation and cell number. In both panels, the time IL- 1 was added to the cultures is shown on the abscissa. $(A)$ Autoradiography ( $24 \mathrm{~h})$. Fibroblasts were pulsed with $\left[{ }^{3} \mathrm{H}\right]$ thymidine at $t=0(0.1 \mu \mathrm{Ci} / \mathrm{ml})$ and harvested for autoradiography at $24 \mathrm{~h}$. Shown is the percent of the maximum growth response observed $(71 \pm 3 \%$ labeled nuclei) as a function of the time IL-1 was added. (B) Cell number. Shown are the numbers of fibroblasts $72 \mathrm{~h}$ after IL-1 addition, expressed as the percent of the maximum growth response observed ( $82 \pm 6 \%$ increase in cell number).

is an accumulation of connective tissue elements within the alveolar structures, a process that contributes to the loss of functional alveolar-capillary units. The process that results in this expansion of the fibroblast population appears to be increased fibroblast replication. A number of studies in animal models of lung fibrosis (33-35) have clearly documented the importance of fibroblast replication, and although there is no direct evidence in humans, it is highly likely that the process is the same. Thus, understanding the signals that influence fibroblast replication is central to an understanding of the pathogenesis of pulmonary fibrosis.

\section{Mononuclear phagocyte modulation of fibroblast replication}

Within the lower respiratory tract, the alveolar macrophage is a major source of growth regulatory signals for fibroblasts. This is consistent with a large number of studies documenting the ability of mononuclear phagocyte secretory products to modulate fibroblast replication in a variety of systems $(1,2,4,6-9,36$, 37). In humans and animals, both blood monocytes and tissue macrophages release growth factors as well as growth inhibitory substances. Among the characterized mediators that can be released by human alveolar macrophages that are potentially important as modulators of fibroblast replication are fibronectin, AMDGF, IFN $\gamma, \mathrm{PGE}_{2}$, and IL-1.

Fibronectin. A 440,000-D glycoprotein, fibronectin plays a central role in cell-cell and cell-connective tissue matrix interactions (38). In addition to its activity as a fibroblast chemoattractant $(5,39)$, fibronectin provides the first of two required signals in the $G_{1}$ phase of the cell cycle (competence) stimulating nonreplicating lung fibroblasts to begin the process of replication (4). While fibronectin is a normal constituent of the alveolar epithelial lining fluid, in the fibrotic lung disorders, its concen- 
tration is increased two- to fivefold (40). One important source of fibronectin in the lower respiratory tract is the alveolar macrophage with a production that is increased up to 20 -fold in the fibrotic lung disorders (5).

$A M D G F$. AMDGF is an $18,000-\mathrm{D}$ peptide growth factor that provides the second of two required signals in $G_{1}$ (progression) inducing nonreplicating fibroblasts to divide (2). Together, fibronectin and AMDGF are sufficient to signal nonreplicating fibroblasts to divide in defined medium (4). While not released in detectable amounts by alveolar macrophages from normal individuals, alveolar macrophages from most patients with progressive fibrotic lung disease spontaneously release substantial quantities of AMDGF consistent with its potential relevance to the evolution of pulmonary fibrosis (3).

Interferon- $\gamma$. IFN $\gamma$, a $25,000-\mathrm{D}$ product of mononuclear phagocytes and $\mathrm{T}$ lymphocytes, does not modulate lung fibroblast replication alone or in response to other exogenous signals. This observation contrasts with the profound inhibition of the replication of certain transformed cells by IFN $\gamma$ (17), and with the ability of IFN $\gamma$ to augment $\mathrm{T}$ lymphocyte replication apparently by inducing IL-2 receptor expression (28) as well as synovial cell and skin fibroblast replication in serum (41). Therefore, although IFN $\gamma$ is released in increased amounts by mononuclear phagocytes from patients with at least one type of interstitial lung disorder (sarcoidosis) (15), it is unlikely to have a major direct effect on the evolution of the fibrotic process in the lung.

$P G E_{2}$. A cyclooxygenase metabolite of arachidonic acid, $\mathrm{PGE}_{2}$ is capable of inhibiting lung fibroblast replication in defined medium in response to two of the important growth factors in the fibrotic lung disorders, fibronectin and AMDGF. This is consistent with the known observation that $\mathrm{PGE}_{2}$ inhibits the replication of mesenchymal cells that have been signaled to divide by serum. For example, Ko et al. (19) have documented the ability of $\mathrm{PGE}_{2}$ to inhibit the replication of serum-stimulated dermal fibroblasts in a dose related manner. The potential relevance of $\mathrm{PGE}_{2}$ to lung fibroblast replication is suggested by direct estimates of $\mathrm{PGE}_{2}$ concentrations within the alveolar epithelial lining fluid. These measurements indicate values in the $10-20 \mathrm{ng} / \mathrm{ml}$ range in normal individuals (42), concentrations clearly capable of influencing fibroblast replication. However, consistent with it being an environment that promotes fibroblast replication, preliminary studies of the epithelial lining fluid concentration of $\mathrm{PGE}_{2}$ in patients with fibrotic lung disorders indicates values only $1 / 3$ to $1 / 2$ of that in normals.

Mononuclear phagocytes from blood and lung, as well as from other sites, in both animals and human are able to produce $\mathrm{PGE}_{2}$, and when appropriately stimulated, can be induced to increase this production several-fold (43-46). In addition, mononuclear phagocytes from both lung $(47,48)$ and blood $(49)$ release a macromolecule(s) capable of inducing $\mathrm{PGE}_{2}$ production by fibroblasts, providing a possible mechanism for autocrine modulation of fibroblast replication.

IL-1. IL-1, a 12,000 to $15,000-\mathrm{D}$ mediator, is able to augment growth factor-induced lung fibroblast replication. Previous reports of the ability of IL- 1 to stimulate fibroblast replication have emphasized the property of IL-1 as a co-stimulator, consistent with its role in thymocyte replication (50). Schmidt et al. (6) demonstrated the ability of IL-1 to augment the replication of serum-stimulated, but not serum-free cultures of skin fibroblasts. Similarly, Estes and co-workers (22) found that IL-1 could augment murine $3 \mathrm{~T} 3$ cell replication in cultures containing optimal concentrations of progression factors only if small to moderate amounts of PDGF (a competence factor) were present. In the absence of PDGF, no amount of IL-1 was effective. These observations are consistent with the concept that IL-1 does not provide a primary (competence or progression) signal for cellular replication, but rather augments the ability of a target cell to respond to these signals.

To be effective, IL-1 was required during the early portion of the $G_{1}$ phase of the cell cycle, the interval when a competence signal is required for fibroblast replication. While IL-1 is clearly incapable of providing a competence signal to either human lung fibroblasts or murine 3T3 cells, it is capable of increasing cellular replication in response to submaximal concentrations of a competence factor. There are two separate implications of this observation: (a) IL-1 may be involved in some part, but not all, of the process of competence formation; and $(b)$ scrupulous removal of all PDGF or other competence factors is required in any growth assay assessing the effects of IL-1 as a primary growth signal since small amounts of PDGF (or serum) in the culture system will result in fibroblast replication and the misinterpretation of IL-1 as a competence factor.

The potential role of IL-1 in lung fibrosis remains undefined. Given its modest ability to augment fibroblast replication, IL-1 likely has a relatively minor role in the fibrotic process in the lung. Consistent with this concept, in contrast to blood monocytes, alveolar macrophages have a limited ability to release IL1 (21). However, in conditions such as sarcoidosis where the alveolar macrophage population is more "monocyte-like" (51), it is likely that IL-1 may be more readily released by the alveolar macrophage population than in normal individuals (52).

\section{Therapeutic implications}

The present study suggests at least two possible therapeutic approaches to the interruption of the fibrotic process in interstitial lung disorders: $(a)$ inhibiting alveolar macrophage release of fibronectin and AMDGF and/or $(b)$ increasing the $\mathrm{PGE}_{2}$ concentration in the alveolar epithelial lining fluid. In this regard, note that in idiopathic pulmonary fibrosis (a chronic progressive interstitial lung disorder), glucocorticoids, the mainstay of therapy, result in long-term improvement in only a small proportion of patients. Consistent with this knowledge, corticosteroids fail to suppress fibronectin and AMDGF release (53).

While there is no information on modulating lower respiratory tract $\mathrm{PGE}_{2}$ levels, preliminary studies in vitro suggest that modulating macrophage release of fibronectin and AMDGF may be possible (54). In this context, colchicine in vitro leads to a dose related decrease in both fibronectin and AMDGF release by alveolar macrophages, suggesting a possible role in the treatment of patients with progressive pulmonary fibrosis. An understanding of the signals within the alveolar microenvironment that are relevant to fibroblast accumulation will, we hope, lead to other rational therapeutic modalities.

\section{References}

1. Leibovich, S. J., and R. Ross. 1976. A macrophage-dependent factor that stimulates the proliferation of fibroblasts in vitro. Am. J. Pathol. 84:501-513.

2. Bitterman, P. B., S. I. Rennard, G. W. Hunninghake, and R. G. 
Crystal. 1982. Human alveolar macrophage growth factor for fibroblast. Regulation and partial characterization. J. Clin. Invest. 70:806-822.

3. Bitterman, P. B., S. Adelberg, and R. G. Crystal. 1983. Mechanisms of pulmonary fibrosis: spontaneous release of the alveolar macrophage derived growth factor in the interstitial lung disorders. J. Clin. Invest. 72:1801-1813.

4. Bitterman, P. B., S. I. Rennard, S. Adelberg, and R. G. Crystal. 1983. Role of fibronectin as a growth factor for fibroblasts. J. Cell Biol. 97:1925-1932.

5. Rennard, S. I., G. W. Hunninghake, P. B. Bitterman, and R. G. Crystal. 1981. Production of fibronectin by the human alveolar macrophage: mechanism for the recruitment of fibroblasts to sites of tissue injury in interstitial lung disease. Proc. Natl. Acad. Sci. USA. 78:71477151.

6. Schmidt, J. A., S. B. Mizel, D. Cohen, and I. Green. 1982. Interleukin-1, a potential regulator of fibroblast proliferation. J. Immunol. 128:2177-2182.

7. Schmidt, J. A., C. N. Oliver, J. L. Lepe Zuniga, I. Green, and I. Gerv. 1984. Silica-stimulated monocytes release fibroblast proliferation factors identical to interleukin-1. A potential role for interleukin-1 in the pathogenesis of silicosis. J. Clin. Invest. 73:1462-1472.

8. DeLustro, F., G. K. Sherer, and E. C. LeRoy. 1980. Human monocyte stimulation of fibroblast growth by a soluble mediator(s). Res. J. Reticuloendothel. Soc. 28:519-532.

9. Glenn, K. C., and R. Ross. 1981. Human monocyte-derived growth factor(s) for mesenchymal cells: activation of secretion by endotoxin and concanavalin A. Cell. 25:603-615.

10. Thet, L. A., and J. D. Crapo. 1982. Morphometry of ultrastructural changes in the lung due to radiation injury. Am. Rev. Respir. Dis. 125(Part 2):229.

11. Crapo, J. D., M. Peters-Golden, J. Marsh-Salin, and J. S. Shelburne. 1978. Pathologic changes in the lungs of oxygen-adapted rats: a morphometric analysis. Lab. Invest. 39:640-653.

12. Carrington, C. B., E. A. Gaensler, J. P. Mikos, A. W. Schachter, G. W. Burke, and A. M. Goff. 1976. Structure and function in sarcoidosis. Ann. NY Acad. Sci. 278:265-283.

13. Spencer, H. 1967. Interstitial pneumonia. Annu. Rev. Med. 18: 423-442.

14. Rinderknecht, E., B. H. O'Connor, and H. Rodriquez. 1984. Natural human interferon- $\gamma$. Complete amino acid sequence and determination of sites of glycosylation. J. Biol. Chem. 259:6790-6797.

15. Robinson, B. W. S., T. McLemore, and R. G. Crystal. 1985. Gamma interferon is spontaneously released by alveolar macrophages and lung T-lymphocytes in patients with pulmonary sarcoidosis. J. Clin. Invest. 75:1488-1495.

16. Epstein, L. B. 1979. The comparative biology of immune and classical interferons. In Biology of the Lymphokines. S. Cohen, E. Pick, and J. Oppenheimer, editors. Academic Press, Inc., New York. 443514.

17. Blalock, J. E., J. A. Georgiades, M. P. Langford, and A. M. Johnson. 1980. Purified human immune interferon has more potent anticellular activity than fibroblast or leukocyte interferon. Cell Immunol. 49:390-394.

18. Taylor, L., and P. Polger. 1977. Self regulation of growth by human diploid fibroblasts via prostaglandin production. FEBS (Fed. Eur. Biochem. Soc.) Lett. 79:69-72.

19. Ko, S. D., R. C. Page, and A. S. Narayaran. 1977. Fibroblast heterogeneity and prostaglandin regulation of subpopulations. Proc. Natl. Acad. Sci. USA. 74:3429-3432.

20. Schmidt, V. A. 1984. Purification and partial biochemical characterization of normal human interleukin 1. J. Exp. Med. 160:772-787.

21. Wewers, M. D., S. I. Rennard, A. J. Hance, P. B. Bitterman, and R. G. Crystal. 1984. Normal human alveolar macrophages obtained by bronchoalveolar lavage have a limited capacity to release interleukin-1. J. Clin. Invest. 2208-2218.

22. Estes, J. E., W. J. Pledger, and G. Y. Gillespie. 1984. Macrophage- derived growth factor for fibroblasts and interleukin-1 are distinct entities. J. Leuk. Biol. 35:115-128.

23. Engvall, E., and E. Ruoslahti. 1977. Binding of soluble form of fibroblast surface protein, fibronectin, to collagen. Int. J. Cancer. 20:1-5.

24. Hayashi, M., and K. M. Yamada. 1981. Differences in domain structures between plasma and cellular fibronectins. J. Biol. Chem. 256: 11292-11300.

25. Rennard, S. I., R. Berg, G. R. Martin, J. M. Foidart, and P. Gehron-Robey. 1980. Enzyme-linked immunoassay (ELISA) for connective tissue components. Anal. Biochem. 104:205-214.

26. Vogel, A., E. Raines, B. Kariya, M. J. Rivest, and R. Ross. 1978. Coordinate control of $3 \mathrm{~T} 3$ cell proliferation by platelet-derived growth factor and plasma components. Proc. Natl. Acad. Sci. USA. 75:28102814.

27. Pledger, W. J., C. D. Stiles, H. N. Antoniades, and C. D. Scher. 1978. An ordered sequence of events is required before BALB/C-3T3 cells become committed to DNA synthesis. Proc. Natl. Acad. Sci. USA. 75:2839-2843.

28. Johnson, H. M., and W. L. Farrar. 1983. The role of a gammainterferon like lymphokine in the activation of T-cells for expression of interleukin-2 receptors. Cell. Immunol. 75:154-159.

29. Bitterman, P. B., L. E. Saltzman, S. Adelberg, V. J. Ferrans, and R. G. Crystal. 1984. Alveolar macrophage replication: one mechanism for the expansion of the mononuclear phagocyte population in the chronically inflamed lung. J. Clin. Invest. 74:460-469.

30. Scadding, J. G., and K. F. W. Hinson. 1967. Diffuse fibrosing alveolitis (diffuse interstitial fibrosis of the lungs). Correlation of histology at biopsy with prognosis. Thorax. 22:291-304.

31. Brody, A. R., and J. E. Craighead. 1976. Interstitial associations of cells lining air spaces in human pulmonary fibrosis. Virchows Arch. Abt. A. Pathol. Anat. 372:39-49.

32. Hayatdavoidi, G. J. J., B. E. O’Neil, B. E. Barry, B. A. Freeman, and J. D. Crapo. 1981. Pulmonary injury in rats following continuous exposure to $60 \% \mathrm{O}_{2}$ for 7 days. J. Appl. Physiol. 51:1220-1231.

33. Adamson, I. Y. R., and D. H. Bowden. 1976. Pulmonary injury and repair. Organ culture studies of murine lung after oxygen. Arch. Pathol. Lab. Med. 100:640-643.

34. Adamson, I. Y. R., D. H. Bowden, M. G. Cote, and H. P. Witschi. 1977. Lung injury produced by butylated hydroxytoluene. Cytodynamic and biochemical studies in mice. Lab. Invest. 36:26-32.

35. Haschek, W. M., K. M. Reiser, A. J. P. Klein-Szanto, J. P. Kehrer, L. H. Smith, J. A. Last, and H. P. Witschi. 1983. Potentiation of butylated hydroxytoluene-induced acute lung damage by oxygen. Cell kinetics and collagen metabolism. Am. Rev. Respir. Dis. 127:28-34.

36. Crystal, R. G., P. B. Bitterman, S. I. Rennard, and B. A. Keogh. 1983. Interstitial lung disease of unknown etiology: disorders characterized by chronic inflammation of the lower respiratory tract. N. Engl. J. Med. 310(Parts 1 and 2):154-166, 235-244.

37. Evans, M. J., and R. F. Bils. 1969. Identification of cells labelled with activated thymidine in the pulmonary alveolar walls of the mouse. Am. Rev. Respir. Dis. 100:372-378.

38. Akiyama, S. K., and K. M. Yamada. 1983. Fibronectin in disease in connective tissue diseases. B. M. Wagner, R. Fleischmajer, and N. Kaufman, editors. Williams and Wilkins, Baltimore, MD. 55-96.

39. Gauss-Muller, V., H. K. Kleinman, G. R. Martin, and E. Shiffman. 1980. Role of attachment and attractants in fibroblast chemotaxis. J. Lab. Clin. Med. 96:1071-1080.

40. Rennard, S. I., and R. G. Crystal. 1982. Fibronectin in human bronchopulmonary lavage fluid: elevation in patients with interstitial lung disease. J. Clin. Invest. 69:113-122.

41. Brinckerhoff, C. E., and P. M. Guyre. 1985. Increased proliferation of human synovial fibroblasts treated with recombinant immune interferon. J. Immunol. 134:3142-3146.

42. Ozaki, T., S. Rennard, and R. G. Crystal. 1983. Arachidonic acid cyclooxygenase metabolites in lung epithelial lining fluid. Clin. Res. 31:165a (Abstr.) 
43. Morley, J., M. A. Bray, R. W. Jones, D. H. Nugtason, and P. A VanDorp. 1979. Prostaglandin and thromboxane production by human and guinea pig macrophages and leukocytes. Prostaglandins. 17:729746.

44. Engineer, D. M., U. Niederauser, P. J. Piper, and P. Sirois. 1978. Release of mediators of anaphylaxis: inhibition of prostaglandin synthesis and the modification of release of slow reacting substance of anaphylaxis and histamine. Br. J. Pharmacol. 62:61-66.

45. Kunkel, S. L., and R. E. Dugue. 1983. The macrophage adherance phenomenon: its relationship to prostaglandin $\mathrm{E}$ ? and superoxide anion production and changes in transmembrane potential. Prostaglandins. 26:893-904.

46. Humes, J. L., R. J. Bonney, L. Pelus, M. E. Dahlgren, S. J. Schowski, F. A. Kuehl, and P. Davies. 1977. Macrophages synthesize and release prostaglandins in response to inflammatory stimuli. Nature (Lond.). 269:149-150.

47. Elias, J. A., R. B. Zusier, M. D. Rossman, M. L. Berube, and R. P. Daniele. 1984. Inhibition of lung fibroblast growth by lung mononuclear cells. Am. Rev. Respir. Dis. 130:810-816.

48. Clark, J. G., K. M. Kostal, and B. A. Marino. 1982. Modulation of collagen production following bleonycin-induced pulmonary fibrosis in hamsters. J. Biol. Chem. 257:8098-8105.

49. Korn, J. H., P. V. Halushka, and E. C. Leroy. 1980. Mononuclear cell modulation of connective tissue function. Suppression of fibroblast growth by stimulation of endogenous prostaglandin production. J. Clin. Invest. 65:543-554.

50. Rosenwasser, L. J., and C. A. Dinarello. 1981. Ability of human leukocytic pyrogen to enhance phytohemoglutinin induced murine thymocyte proliferation. Cell. Immunol. 63:134-142.

51. Hance, A. J., S. Douches, R. J. Winchester, V. J. Ferrans, and R. G. Crystal. 1985. Characterization of mononuclear phagocyte subpopulations in the human lung using monoclonal antibodies: changes in alveolar macrophage phenotype associated with pulmonary sarcoidosis. J. Immunol. 134:284-292.

52. Hunninghake, C. W. 1984. Release of interleukin-1 by alveolar macrophages of patients with active pulmonary sarcoidosis. Am. Rev. Respir. Dis. 129:569-572.

53. Lacronique, J. G., S. I. Rennard, P. B. Bitterman, T. Ozaki, and R. G. Crystal. 1984. Alveolar macrophages in idiopathic pulmonary fibrosis have glucocorticoid receptors, but glucocorticoid therapy does not suppress alveolar macrophage release of fibronectin and alveolar macrophage derived growth factor. Am. Rev. Respir. Dis. 130:450-456.

54. Rennard, S., P. Bitterman, T. Ozaki, and R. G. Crystal. 1984. Colchicine blocks the release of mediators of fibrosis by human alveolar macrophages. Clin. Res. 32(2):246a (Abstr.) 